\title{
Vegetative response to climate change in the Big Pine Creek watershed along a 2,500 meter elevation gradient using Landsat data
}

\author{
Patrick Shawn Sawyer $^{1}$, Haroon Stephen ${ }^{2}$ \\ ${ }^{1}$ School of Environmental and Public Affairs, University of Nevada, Las Vegas, United States \\ ${ }^{2}$ Department of Civil and Environmental Engineering and Construction, University of Nevada, Las Vegas, United States
}

Email address:

sawyerp2@unlv.nevada.edu (P. Sawyer), haroon.stephen@unlv.edu (H. Stephen)

\section{To cite this article:}

Patrick Shawn Sawyer, Haroon Stephen. Vegetative Response to Climate Change in the Big Pine Creek Watershed along a 2,500 Meter Elevation Gradient Using Landsat Data. Earth Sciences. Vol. 3, No. 6, 2014, pp. 137-146. doi: 10.11648/j.earth.20140306.12

\begin{abstract}
This paper presents a time series study of an alpine ecosystem in the Big Pine Creek watershed in California's Eastern Sierra Nevada Mountain's. Seventy five sample sites along a 2,500 meter elevation gradient are analyzed for trends in surface reflectance based on vegetative density using USGS data derived from Landsat imagery for the 1984 through 2013 time frame. Three vegetative indices, $N D V I, S A V I$, and $M S A V I_{2}$ as well as the Tasseled Cap transformations for Brightness $\left(T C_{B}\right)$, greenness $\left(T C_{G}\right)$, and wetness $\left(T C_{W}\right)$ are explored. We found that over the time period of the study, significant increases in vegetation are occurring at densely vegetated sites at almost all elevations within the watershed while less change and even some significant declines in vegetation are seen in moderately and sparsely vegetated sites. Sparsely vegetated sites show distinct bifurcation in their response with the lower elevations seeing declines and the upper elevations seeing increases in vegetation. Several sites show significant declines in both the visible and near infrared regions suggesting there are compositional changes taking place consistent with climate induced range shifts. This study provides a useful insight into the ecological response of the Big Pine Creek watershed to recent climate change.
\end{abstract}

Keywords: Landsat, Vegetation Indices, Elevation Gradient, Alpine Watershed, Climate Change, Time Series Mann-Kendall Trend Analysis

\section{Introduction}

Alpine ecosystems are crucial laboratories for the study of how changing climatic variables will impact local species assemblages. The steep elevation gradients in these regions provides for analysis of several ecotones within a small area. The biomes that inhabit these areas are particularly susceptible to changing environmental parameters since many exist at the limits of their ranges [1]. While many studies have identified biotic response to climate change over large regions, the response at the local and individual ecosystem level are necessary to understand population dynamics that underlie range shifts $[2,3]$.

Existing research has focused on the response of individual species, often overlooking important biotic and abiotic interactions that drive community assembly. All the life forms within a local community interact with each other and their physical world forming a complex intricate fabric that identifies the characteristic traits of that assemblage. The predicted trend in climate induced range shifts is for increased extinctions at the warm boundaries and species expansions at the cold range limits [2]. However, in alpine regions, the loss of space with elevation will lead upslope migrating species into a summit trap which will drive extinction rates higher $[4,5]$.

Since the response rate to altered environmental conditions varies among each member of the local assemblage, climate change will drive significant alteration of the interactions between the individual components and the overall functioning of the local community. Changes in the timing and availability of resources can have significant negative impacts on individual species survival rates while at the same time providing opportunities for competition to allow replacement species to prosper [6]. An ongoing study of the Global Observation Research Initiative in Alpine Environments (GLORIA) site in the European Alps demonstrates this process as species richness has shown a $12 \%$ increase in only a 10 year period [7]. 
Previous studies have examined the climate induced shift in range limits for species. Kelly and Goulden, (2008) found that the average elevation of the dominant plant species rose by about 65 meters over a 30 year period along an elevation gradient of 2,314 meters in the Santa Rosa Mountains of Southern California [8]. The study area consisted of arid to semi-arid regions dominated by desert scrub in the lower reaches, pinyon-juniper woodlands as you move upslope, followed by chaparral scrubland and conifer forest in the higher reaches. Total plant cover was stable over the study period. Half of the sample sites had modest increases while half showed modest declines [8].

However, while total cover was stable, species distribution showed significant change with an average elevation gain of 65 meters. This study found that instead of migration of new species into new territory, most of the observed changes were related to a shift in dominance within local assemblages [8]. This is an important finding in that significant compositional changes were observed even though overall range limits were stable. Regional studies that focus on range shifts may miss important changes at the local community level.

Habitat density plays an essential role in determining the local response to climate change. Once the critical population for a specific resource falls below sustainment levels, a chain reaction can occur that fundamentally alters the composition and functioning of the local grouping. Altered environmental parameters such as warmer temperatures or reduced moisture availability can leave individual species in a weakened state, allowing for rapid infestation of predator or competitor species. While natural selection can lead to the development of tolerance traits that enhance the survivability of individual species, this process will most likely take much longer than the changes to the habitat which are driving species extinction [6].

Spectral characteristics measured with remote sensing instruments such as the Landsat 5 Thematic Mapper (TM) and Landsat 7 Enhanced Thematic Mapper $\left(\mathrm{ETM}^{+}\right)$enable us to analyze ecological properties of vegetation. Vegetation has characteristic spectral responses such as low red reflectance due to chlorophyll absorption and high near infrared (NIR) reflectance due to the reflectance of the internal structures of the canopy [9]. Changes in surface reflectance can thus be correlated with variation in vegetative cover and plant health. Since the constituents of the plants vary over their phenological cycle, it is also possible to identify the various stages of the cycle such as spring flowering and fall senescence. Changes in the timing of these cycles can serve as an indicator of climate change.

Soil also demonstrates unique spectral characteristics depending on properties such as its moisture, organic matter content and texture [10]. Lower soil moisture content, a possible indicator of water stress in vegetation, would cause higher surface reflectance in the mid-wave infrared (MWIR) region that can be detected using Landsat data [11]. Higher temperatures combined with lower humidity levels will increase evapotranspiration resulting in less soil and vegetation moisture which will place additional burden on ecosystem vegetation. These effects are heightened in regions experiencing historic droughts such as the southwestern United States [12]. Jackson et al. (1986) found that plant water stress will decrease the NIR response while increasing the reflectance in the red region of the spectrum. In addition to altering the spectral reflectance properties of the vegetation, plant stress can alter the geometry of the plant through processes such as drooping or wilting, resulting in a higher soil fraction component of the response signal [10]. Todd and Hoffer (1998) found that reduced vegetation moisture content tends to increase visible and MWIR reflectance [13].

Vogelmann et al. (2009) examined trends in spectral response in a time series study of the San Pedro Parks Wilderness area in New Mexico for the years 1992 through 2006. Higher elevations were shown to be spectrally stable except for areas infested with western spruce budworm. Some of the lower elevation shrub regions had declines in their short-wave infrared (SWIR)/NIR ratios as did patches of conifer trees suffering from high mortality rates [14]. Loss of available moisture significantly impacts forest growth and overall ecosystem health [15]. Higher temperatures may also promote pest infestation. Williams et al. (2013) found that bark beetle populations increased during warmer periods, especially in forests already suffering moisture deficits induced by higher temperatures. This study determined that maximum temperature $\left(\mathrm{T}_{\mathrm{MAX}}\right)$ is an ideal surrogate for determining vapor pressure deficit induced forest stress [15].

The ecological response to elevated temperatures and $\mathrm{CO}_{2}$ levels is complex and will be affected by other factors such as water and other nutrient resource availability. In cold alpine regions where water availability is not limiting, higher temperatures are expected to increase the habitable zones for several species, allowing for upslope migration and increased vegetative cover. In alpine regions, higher temperatures combined with increased atmospheric $\mathrm{CO}_{2}$ levels will increase photosynthesis resulting in increased biomass; provided other essential resources are not limited [16]. Conversely, where water is limited, higher temperatures will increase plant stress resulting in reduced vegetative cover [17].

In this study we explore ecosystem response to recent climate change by analyzing trends in surface reflectance across a 2,500 meter elevation gradient in an alpine watershed using time series analysis of Landsat surface reflectance data. We apply a statistical approach to determine the presence of trends in the data that would validate the hypothesis of increased biomass resulting from higher temperature and atmospheric $\mathrm{CO}_{2}$ levels in resource rich areas. Increased biomass is inferred by evidence of increased vegetative surface cover. We also look for evidence that species composition has been changing as evidenced by changes in the spectral fingerprint for each sample site over time. We present this information by first describing the study area and the data used in the analysis, we then discuss the research approach and methods used to collect and process the data, followed by our results and conclusions. We 
hypothesize that sites with no resource limitations, (i.e. those nearest a water source), will show an increase in vegetative cover while sites with limited resources will show a decrease in the vegetative cover. We also hypothesize that sites at the limits of species ranges will show compositional change.

\section{Study Area and Data}

\subsection{Study Area Description}

Fig. 1 below shows the Big Pine Creek watershed located in California's Eastern Sierra Mountains. Big Pine Creek is a major tributary to the Owens River which is a significant source of fresh water for Los Angeles. The Owens River valley straddles the Great Basin and Mojave deserts with vegetation consisting primarily of pine forests at higher elevations and xeric species at lower elevations. Areas bordering streams and the Owens River are primarily grass dominated meadows [18]. Elevation within the watershed increases from East to West with the higher regions dominated by barren rock and woodlands with the lower regions dominated by mixed desert shrubs.

Big Pine Creek Watershed on the Eastern Slopes of California's Eastern Sierra Mountains

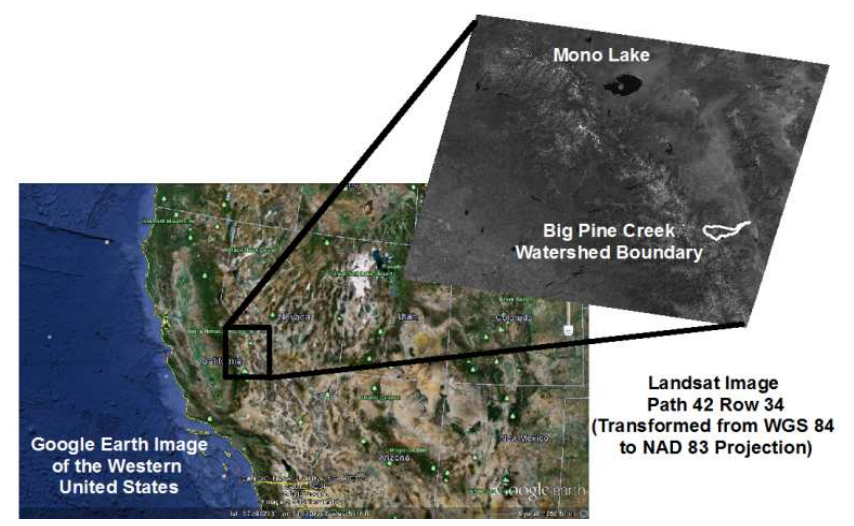

Figure 1. Study area location showing the boundary of the Big Pine Creek watershed.
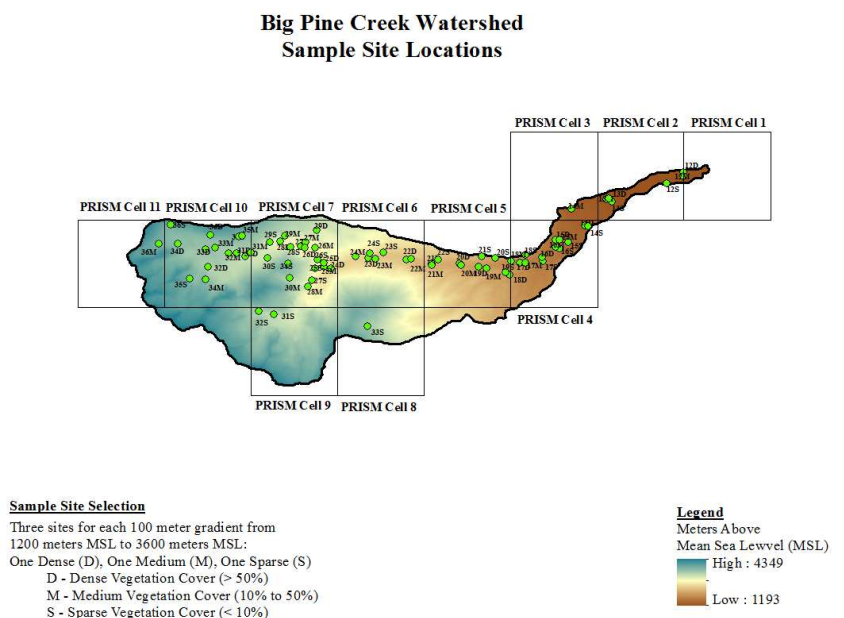

Figure 2. Sample Site Locations.
The Big Pine Creek watershed ecosystem owes its existence to snow melt and melt-water from the Palisade Glacier. In addition to being the southern-most glacier in the United States, it is also the largest glacier in the Sierras with a surface area of $1.3 \mathrm{~km}^{2}$. It was formed about 3,200 years ago, reaching a maximum extent as recently as 170 years ago [19]. It has been generally in retreat ever since. The Big Pine Creek watershed drainage area covers approximately $82 \mathrm{~km}^{2}$ and its average flow is $1.8 \mathrm{~m}^{3} / \mathrm{s}$. Measurements taken in the 1980's indicate that the creek is a gaining stream at the lower elevations in contrast to most other Owens River tributaries which are losing streams [20]. Since all of the living species within this watershed depend on the glacier and snow melt for their survival, the impact of temperature and precipitation variations on the biodiversity of the Big Pine Creek watershed is the focus of this study.

Three sample sites were selected at each 100 meter elevation gradient from 1200 meters above sea level (asl) at the base of the watershed to 3600 meters asl at the top. At each elevation, a densely vegetated site, a moderately vegetated site and a sparsely vegetated site were selected. Vegetation density at each elevation was determined by visual analysis of Google Earth satellite imagery. In general, the densely vegetated sites show surface cover exceeding $50 \%$, the moderately vegetated sites had $10 \%$ to $50 \%$ surface cover and the sparsely vegetated sites were typically barren with less than $10 \%$ cover. The percentage vegetative cover closely correlated to the distance from a water source such as the Big Pine Creek, one of its tributaries, or one of the watershed lakes.

\subsection{Data}

The data in this study consists of Landsat surface reflectance data obtained from the USGS EarthExplorer website.

Table 1. Summary of Landsat imagery used in this analysis.

\begin{tabular}{llll}
\hline Image Date & $\begin{array}{l}\text { Scene ID } \\
\text { (Path/Row) }\end{array}$ & Image Date & $\begin{array}{l}\text { Scene ID } \\
\text { (Path/Row) }\end{array}$ \\
\hline $7 / 13 / 2013$ & $42 / 34$ & $7 / 30 / 1998$ & $42 / 34$ \\
$7 / 28 / 2012$ & $42 / 34$ & $7 / 27 / 1997$ & $42 / 34$ \\
$7 / 18 / 2011$ & $42 / 34$ & $7 / 8 / 1996$ & $42 / 34$ \\
$7 / 31 / 2010$ & $42 / 34$ & $7 / 22 / 1995$ & $42 / 34$ \\
$7 / 5 / 2009$ & $41 / 34$ & $7 / 3 / 1994$ & $42 / 34$ \\
$7 / 25 / 2008$ & $42 / 34$ & $7 / 16 / 1993$ & $42 / 34$ \\
$7 / 7 / 2007$ & $42 / 34$ & $7 / 29 / 1992$ & $42 / 34$ \\
$7 / 13 / 2006$ & $41 / 34$ & $7 / 27 / 1991$ & $42 / 34$ \\
$7 / 1 / 2005$ & $42 / 34$ & $7 / 8 / 1990$ & $42 / 34$ \\
$7 / 30 / 2004$ & $42 / 34$ & $7 / 5 / 1989$ & $42 / 34$ \\
$7 / 12 / 2003$ & $42 / 34$ & $7 / 2 / 1988$ & $42 / 34$ \\
$7 / 25 / 2002$ & $42 / 34$ & $7 / 25 / 1987$ & $41 / 34$ \\
$7 / 22 / 2001$ & $42 / 34$ & $7 / 13 / 1986$ & $42 / 34$ \\
$7 / 19 / 2000$ & $42 / 34$ & $7 / 3 / 1985$ & $41 / 34$ \\
$7 / 17 / 1999$ & $42 / 34$ & $7 / 7 / 1984$ & $42 / 34$ \\
\hline
\end{tabular}

\subsubsection{Surface Reflectance Data}

The Landsat program has been providing earth observation remote sensing data to the scientific community for four decades. The first Landsat satellite was placed in orbit in 
1972 with Landsat 7 remaining operational today. Landsat 5 was only recently taken off-line. The latest generation satellite, Landsat 8, was launched on February $11^{\text {th }}, 2013$ and is now operational. Data for this study includes imagery from both the Landsat $5 \mathrm{TM}$ and Landsat $7 \mathrm{ETM}^{+}$sensors.

This surface reflectance data product for each of these imagers was obtained from the EarthExplorer web site operated by the United States Geological Survey (http://earthexplorer.usgs.gov/). Since the period of maximum leaf area index generally occurs in the mid-June to mid-August time frame [21], only imagery in the July time frame was considered for this analysis in order to minimize the impacts of the phenological cycle on the reflectance data.

\section{Research Approach and Methods}

\subsection{Research Approach}

This study examines how the surface reflectance of the watershed has changed over the last 30 years. To determine if climate change impacts to the vegetation in the study area have already occurred, we look for trends in the data that indicate alteration of the vegetative composition, health, or quantity. Sample sites are selected at 100 meter elevation gradients to determine if there are specific elevations where changes are most likely to occur. This is accomplished by performing a time series trend analysis of the surface reflectance values in each of the six reflectance bands of the Landsat sensors.

\subsection{Research Methods}

The research methodology consists of data collection; data processing; and statistical analysis. Each step is described below.

\subsubsection{Data Collection}

In order to perform a temporal study comparing the physiological changes over time at each of the sample sites, surface reflectance values for each year of the study period were obtained from the USGS Climate Data Record (CDR) archive.

\subsubsection{Statistical Trend Analysis}

The non-parametric Mann-Kendall (MK) trend test is used to establish the presence of trends in the surface reflectance and meteorological data over the last 30 years. This analysis essentially determines if a set of values $(y)$ are increasing or decreasing over time. Mann-Kendall analysis looks at the sums of the signs of the differences between successive data points and calculates a score or " $\mathrm{S}$ " statistic with the following properties: for $S<0$ (values are decreasing over time); for $S>0$ (values are increasing over time). The magnitude of the S-statistic is a measure of the strength of the trend. For a sample size of $30, S$ values of \pm 111 indicate a statistically significant trend with a $p$ value of $<0.05$. This means the null hypothesis of no-trend in the data can be discarded with the risk of committing a Type II (rejection of a true null or $H_{0}$ ) error at less than 5\%. The MK S-statistic is calculated using (1)

$$
S=\sum_{i=1}^{n-1} \sum_{j=i+1}^{n} \operatorname{sign}\left(y_{j}-y_{i}\right)
$$

where $n$ is the number of observations and $y_{i}(i=1 \ldots n)$ is the value at time $T_{i}$ and $y_{j}(i=1, \ldots, n)$ is the value at time $T_{j}$ [22]. Variance in the $S$ statistic is calculated as

$$
\operatorname{Var}(S)=\frac{n(n-1)(2 n+5)}{18}
$$

This variance assumes there are no tied pairs in the data. If tied pairs are identified, the software program applies a continuity equation which assumes a normal distribution for $\mathrm{S}$ with a zero mean. The variance is used to determine the probability $(p)$ of obtaining a value of $\mathrm{S}$ greater than that calculated for the given number of data points when no trend is present. The probability statistic is determined from the $\mathrm{Z}$ score which is defined as:

$$
Z=\left\{\begin{array}{cc}
\frac{S-1}{\sqrt{\operatorname{Var}(S)}} & , \text { for } S>0 \\
0 & , \text { for } S=0 \\
\frac{S+1}{\sqrt{\operatorname{Var}(S)}} & , \text { for } S<0
\end{array}\right.
$$

In addition to the trend statistic $(S)$, Kendall's tau $(\tau)$ is determined from the equation

$$
\tau=\frac{S}{\frac{n(n-1)}{2}}
$$

where $n$ is the number of observations. Kendall's tau is similar to the correlation coefficient in linear regression. The magnitude of the trend is determined using the Sen's slope estimation with confidence intervals defined as the upper and lower estimate for the mean value of the slope. Sen's slope is determined by calculating the slope at each data point and taking the median of those slopes as the magnitude of the trend as shown;

$$
\text { Sen's Slope }=\text { median }\left(\frac{y_{j}-y_{i}}{\text { Time }_{j}-\text { Time }_{i}}\right)
$$

These calculations are carried out in Excel using the XLSTAT add-in statistical application. This program generates the $\mathrm{S}$ statistic as well as the probability $(p)$ value which is used to quantify the statistical significance of the trend. The confidence factor (risk of rejecting a true null) is defined as $(1-p) * 100 \%$.

\subsubsection{Surface Reflectance Data}

USGS surface reflectance data is generated from a software package known as the Landsat Ecosystem Disturbance Adaptive Processing System (LEDAPS). The surface reflectance data is computed by applying an 
atmospheric correction to the raw Landsat imagery (USGS, 2013). This atmospheric correction uses the Second Simulation of a Satellite Signal in the Solar Spectrum (6S) radiative transfer model to account for various atmospheric column constituents including water vapor, ozone, and aerosol optical thickness [23].

The LEDAPS process uses average daily lamp brightness history to obtain calibration coefficients based on acquisition date. These calibration coefficients are used to determine the at-sensor radiance values [23]. The LEDAPS process converts at-sensor radiance to top-of-atmosphere (TOA) by an algorithm that incorporates solar irradiance derived from the MODTRAN model, bandpass, earth sun distance and solar zenith angle [23].The LEDAPS atmospheric correction assumes particle scattering and gaseous absorption can be decoupled [23]. LEADAPS applies Moderate Resolution Imaging Spectroradiometer (MODIS) atmospheric correction routines to Landsat data that correlates surface reflectance is with TOA reflectance using (6),

$$
\rho_{T O A}=T_{g}\left(O_{3}, O_{2}, \mathrm{CO}_{2}, \mathrm{NO}_{2}, \mathrm{CH}_{4}\right)\left[\rho_{R+A}+T_{R+A} T_{g}\left(\mathrm{H}_{2} \mathrm{O}\right) \frac{\rho_{S}}{1+S_{R+A} \rho_{S}}\right]
$$

where $\rho_{s}$ is the surface reflectance, $T_{g}$ is the gaseous transmission, $T_{R+A}$ is the Rayleigh and aerosol transmission, $\rho_{R+A}$ is the Rayleigh and aerosol atmospheric intrinsic reflectance, and $S_{R+A}$ is the Rayleigh and aerosol spherical albedo [23].

The $6 \mathrm{~S}$ radiative transfer model is used to derive surface reflectance from (6) with the input of aerosol optical thickness (AOT), atmospheric pressure and water vapor. The Total Ozone Mapping Spectrometer (TOMS) carried by the Nimbus 7, Meteor 3 and Earth Probe satellites provides the ozone concentration data. For the 1994 through 1996 time period when TOMS data was unavailable, vertical sounder data from the National Oceanic and Atmospheric Administration (NOAA) was used. Rayleigh scattering is adjusted to local conditions using surface pressure data from NOAA's National Center for Environmental Protection (NCEP) [23].

This atmospheric correction methodology uses a dark dense vegetation procedure developed by Kaufman et al., (1997) to determine AOT from the imagery [24]. This technique is based on the assumption of a linear relationship between surface reflectance in the visible bands and the surface reflectance in the short wave band $(2.2 \mu \mathrm{m}$ where surface reflectance is not affected by the atmosphere) based on the physical correlation between bound water absorption and chlorophyll absorption. Using this procedure to calculate surface reflectance in the visible bands then allows for the determination of AOT by comparing the TOA reflectance to the surface reflectance. Since this technique only determines the AOT in the blue region, a continental aerosol model is used to determine AOT in the other spectral regions. The AOT, atmospheric pressure, ozone and water vapor data are then processed by the $6 \mathrm{~S}$ model to convert TOA reflectance to surface reflectance [23].
The USGS CDR data set provides us with observed surface reflectance values for each of the six reflectance bands for all sample sites in each year of the study. In order to identify the effect of elevation on the ecosystem's response to climate change, we examine trends in surface reflectance at 100 meter gradients from 1200 meters to 3600 meters asl. Additional analysis is performed by examining trends based on vegetative density. We also examine relationships between the spectral bands by considering the trends in vegetation indices resulting from the surface reflectance data.

Vegetation indices are often used to establish vegetation cover in remote sensing studies. We consider both ratio indices which analyze the large difference in the red and NIR bands characteristic of vegetation and weighted ratios which focus on physical parameters such as surface brightness, greenness and wetness. In this analysis we look at the following indices:

Normalized Difference Vegetation Index (NDVI), defined as

$$
N D V I=\frac{\rho_{N I R}-\rho_{R E D}}{\rho_{N I R}+\rho_{R E D}}
$$

[25], where $\rho_{N I R}$ is the reflectance in band 4 and $\rho_{R E D}$ is the reflectance in band 3; Soil Adjusted Vegetation Index (SAVI), defined as

$$
S A V I=(1+L) \frac{\rho_{N I R}-\rho_{R E D}}{\rho_{N I R}+\rho_{R E D}+L}
$$

where $L$ is a soil correction factor set at 0.5 [26]; Modified Soil Adjusted Vegetation Index $\left(M S A V I_{2}\right)$, defined as

$$
M S A V I_{2}=\frac{2 \rho_{N I R}+1-\sqrt{\left(2 \rho_{N I R}+1\right)^{2}-8\left(\rho_{N I R}-\rho_{R E D}\right)}}{2}
$$

[27]; and Tasseled Cap transformations for Brightness $\left(T C_{B}\right)$, Greenness $\left(T C_{G}\right)$, and Wetness $\left(T C_{W}\right)$ which are defined as

$$
\begin{gathered}
T C_{B}=0.2043 \rho_{1}+0.4185 \rho_{2}+0.5524 \rho_{3}+0.5741 \rho_{4}+0.3124 \rho_{5}+0.2303 \rho_{7}(10) \\
T C_{G}=-0.1603 \rho_{1}-0.2819 \rho_{2}-0.4934 \rho_{3}+0.7940 \rho_{4}-0.0002 \rho_{5}-0.1446 \rho_{7}(11) \\
T C_{W}=0.0315 \rho_{1}+0.2021 \rho_{2}+0.3102 \rho_{3}+0.1594 \rho_{4}-0.6806 \rho_{5}-0.6109 \rho_{7}(12)
\end{gathered}
$$

where $\rho_{1 \ldots .}$ is the reflectance in band 1 through band 7 respectively [28].

\section{Results and Discussion}

\subsection{Spectral Trend Data}

Figure 3 summarizes the trends in surface reflectance data for densely vegetated sites by elevation gradient. These graphs demonstrate significant declines in the visible bands 1 , 2 , and 3 below the 2600 meter level. Declines in the visible bands are consistent with increased vegetation due to higher chlorophyll absorption. The near infrared, band 4, shows positive trends at most elevations. This finding is consistent 
with increased structural complexity at those sites as near infrared reflectance increases with increasing surface structural features. The trends in band 5 reflectance are mixed with no consistent pattern. This spectral region is where the water absorption feature exists which means sites showing significant declines are indicative of higher water content from which we infer increased vegetation cover. In the band 7 region, most of the sites show declines regardless of elevation which is consistent with increased surface cover as this region is correlated with surface brightness.

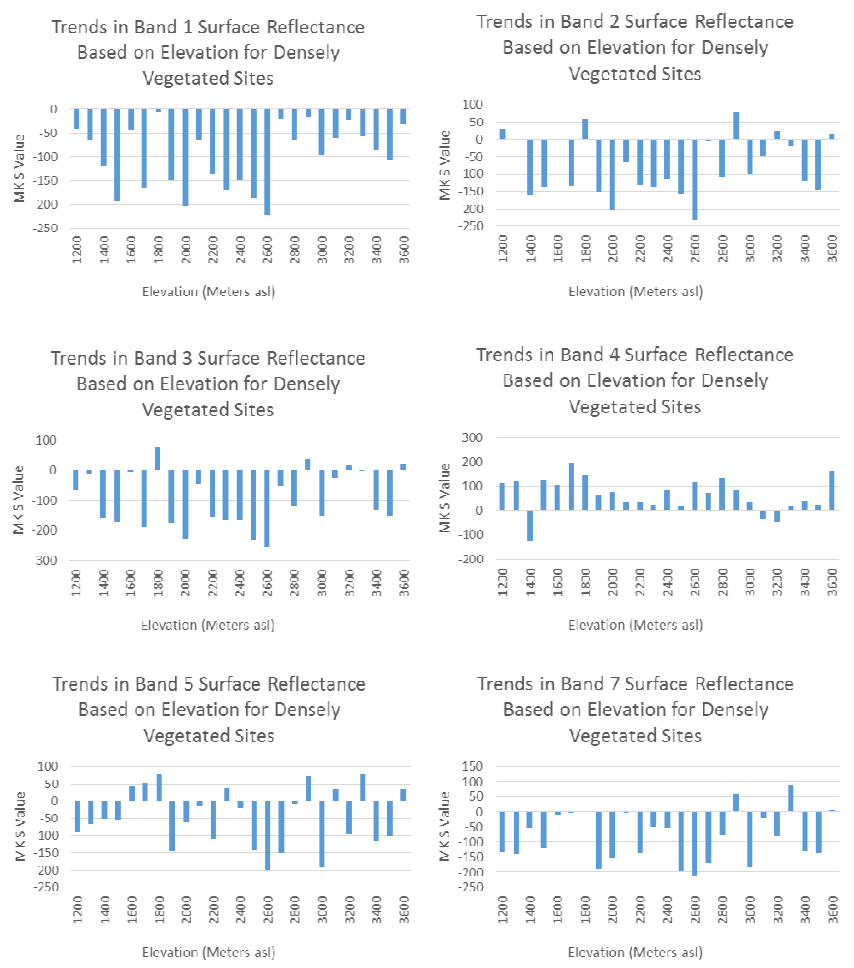

Figure 3. Trends in surface reflectance for densely vegetated sites.

Figure 4 summarizes the trends in surface reflectance data for moderately vegetated sites by elevation gradient. These graphs demonstrate that for moderately vegetated sites, the most significant changes are taking place at the upper reaches of the watershed at the 3300 meter to 3600 meter asl elevations. Below that level, the trends do not show a distinct elevation dependency. However, in the band 5 and band 7 regions, the lower reaches of the watershed show decreased surface moisture along with increased surface brightness respectively. These findings are consistent with declines in vegetation for moderately vegetated sited below 1800 meters asl.
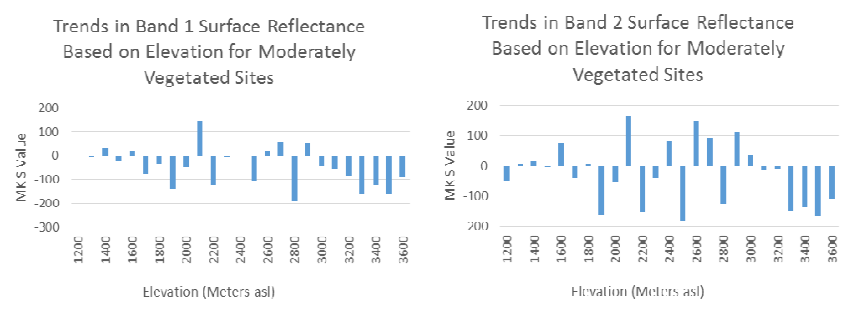

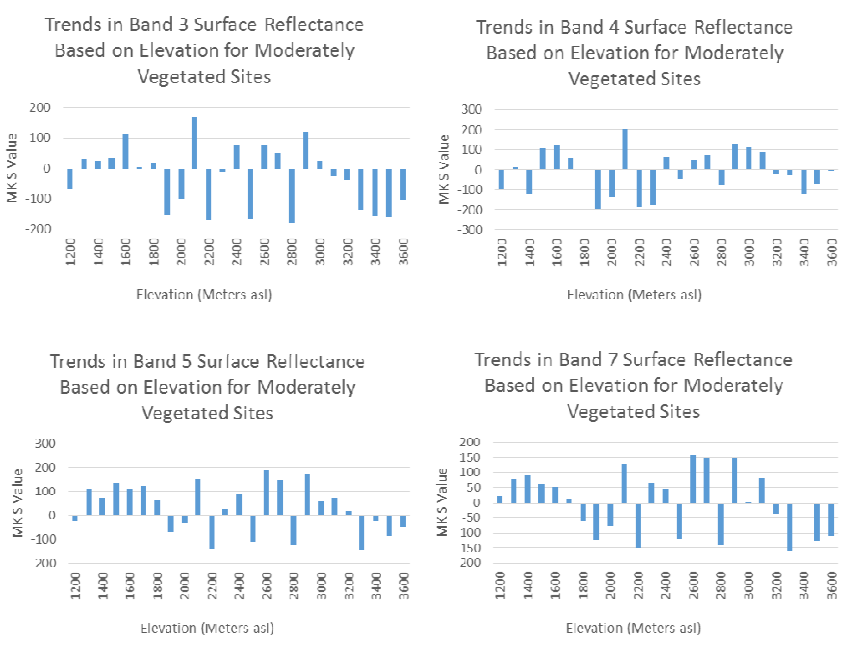

Figure 4. Trends in surface reflectance for moderately vegetated sites.

Although no clear elevation correlation is seen in the middle third of the study area (1900 meters to 2900 meters asl), several of the moderately vegetated sites show statistically significant changes with the data suggesting declining vegetation at the 2100 meter and 2900 meter asl sites and significant increases at the 1900 meter, 2200 meter, 2500 meter, and 2800 meter asl sites. The variation in the individual band responses suggests compositional changes are also taking place.

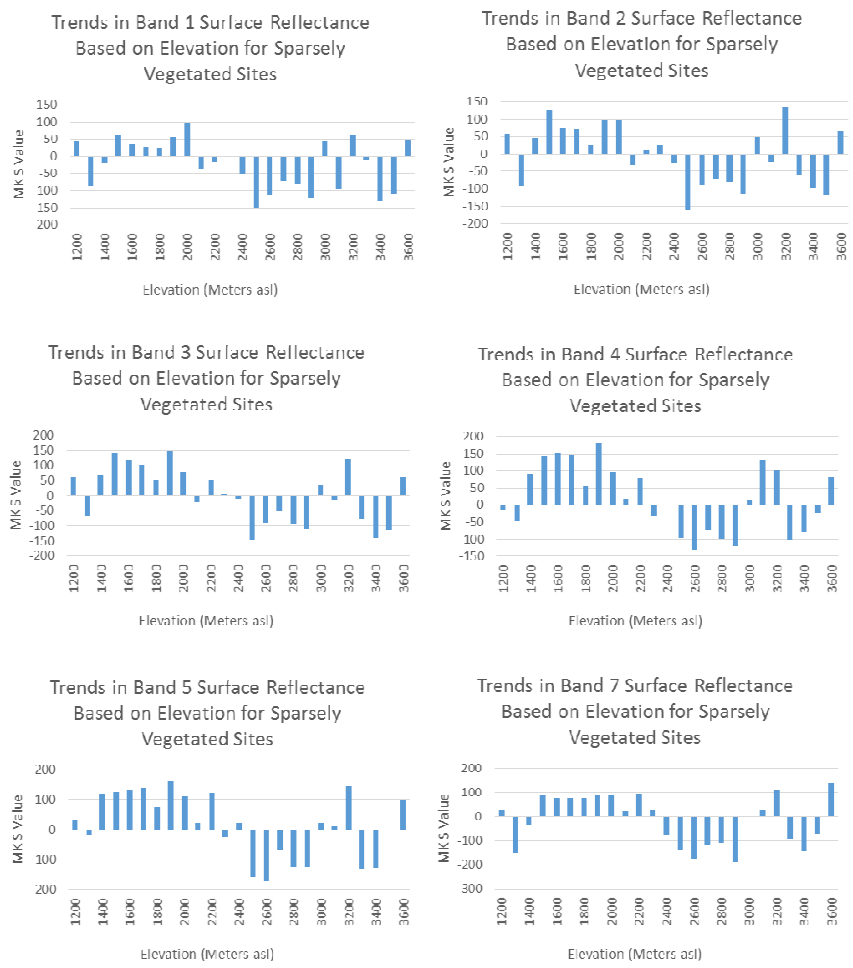

Figure 5. Trends in surface reflectance for sparsely vegetated sites.

Figure 5 summarizes the trends in surface reflectance data for sparsely vegetated sites by elevation gradient. These graphs demonstrate that for sparsely vegetated sites, there is a distinct bifurcation in spectral responses by elevation with 
increasing surface reflectance in the lower half of the watershed and decreasing reflectance in the upper half of the watershed for all six bands. There is a distinct transition range from 2200 meters to 2400 meters asl where the increases in reflectance switch to declines.

These findings suggest that in sparsely vegetated sites, vegetative surface cover is declining in the lower elevations while increasing at the higher elevations. The fact that the near infrared region response matches the visible response is consistent with a change in composition over the time period of the study. These findings support the hypothesis of upslope migration at the upper limits into newly habitable zones and an associated decline in population at the lower range limits where heat and moisture stressors are reducing habitability.

Figure 6 shows the trends for vegetation indices and Tasseled Cap transformations for densely vegetated sites. These results suggest a nearly uniform increase in vegetation with the exception of the 3000 meter to 3400 meter asl zone. The three indices (NDVI, SAVI, and $\left.M S A V I_{2}\right)$ along with the tasseled cap greenness transformation $\left(T C_{G}\right)$ show consistent patterns. The general declines in tasseled cap brightness $\left(T C_{B}\right)$ are also consistent with increased vegetative surface cover as are the general increases in tasseled cap wetness $\left(T C_{W}\right)$.

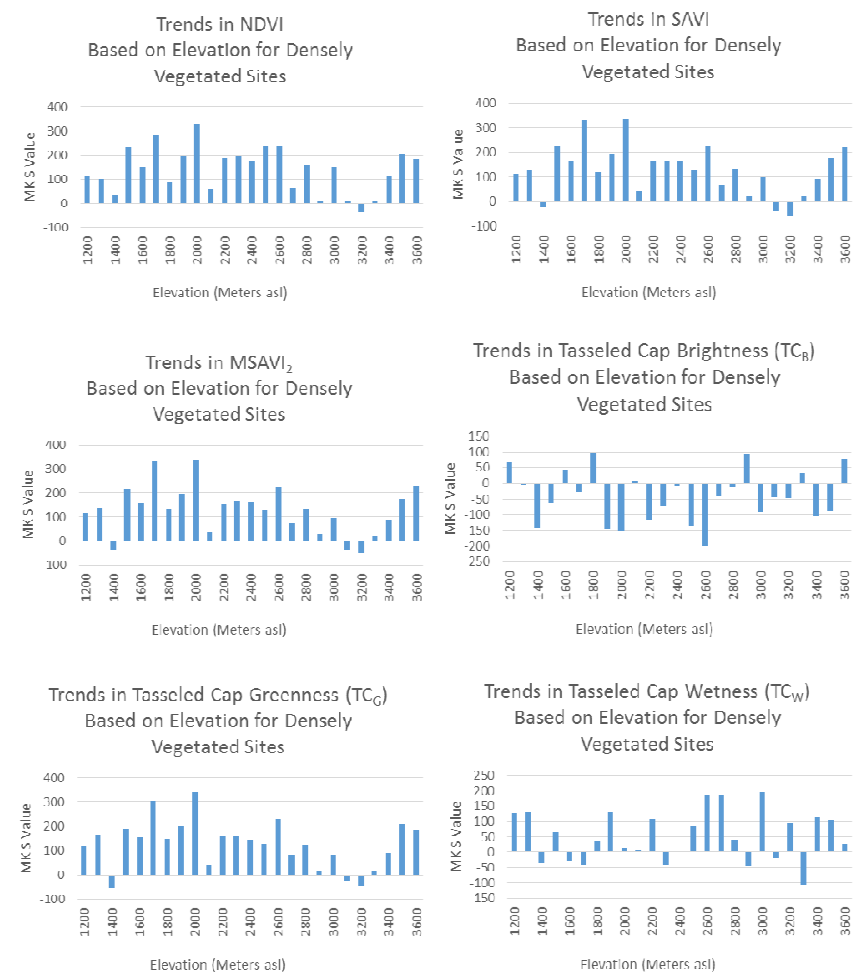

Figure 6. Trends in vegetation indices for densely vegetated sites.

These results mirror the trends in the spectral response. Both the spectral trends and the trends in the vegetation indices and transformations are consistent with a significant increase in vegetation throughout the study area in densely vegetated sites. This supports our hypothesis that sites without resource limitations, higher temperatures and $\mathrm{CO}_{2}$ levels will boost photosynthetic activity resulting in increased vegetation and biomass.
The lack of change in the 3000 meter to 3400 meter asl zone is most likely due to unique characteristics of those sites and suggest that those locations lack the resources to take advantage of the increases temperature and $\mathrm{CO}_{2}$ levels.

Figure 7 shows that for moderately vegetated sites, the vegetation indices and tasseled cap transformations do not indicate any significant patterns associated with elevation gradient. As with the trends in spectral response, these findings suggest an increase in vegetation at the higher elevations (above 2800 meters asl). The declines in the wetness values along with the increases in brightness values below 1800 meters asl suggest declining vegetative surface cover resulting from increased moisture stress at those sites.

The strong declines at the 2100 meter asl site seen in the spectral response is also reflected in the trends in the vegetation indices while the evidence for significant declines at the 2900 meter asl site suggested by the spectral trend data are not evident in the vegetation indices. For the sites where spectral trends suggest significant increases, (1900 meter, 2200 meter, 2500 meter, and 2800 meter asl), trends in vegetation indices are not as significant. However, the tasseled cap brightness values for those sites do show significant declines suggesting increased ground cover. The fact that the vegetation indices do not coincide with the spectral response trends is consistent with a compositional change taking place at those sites.

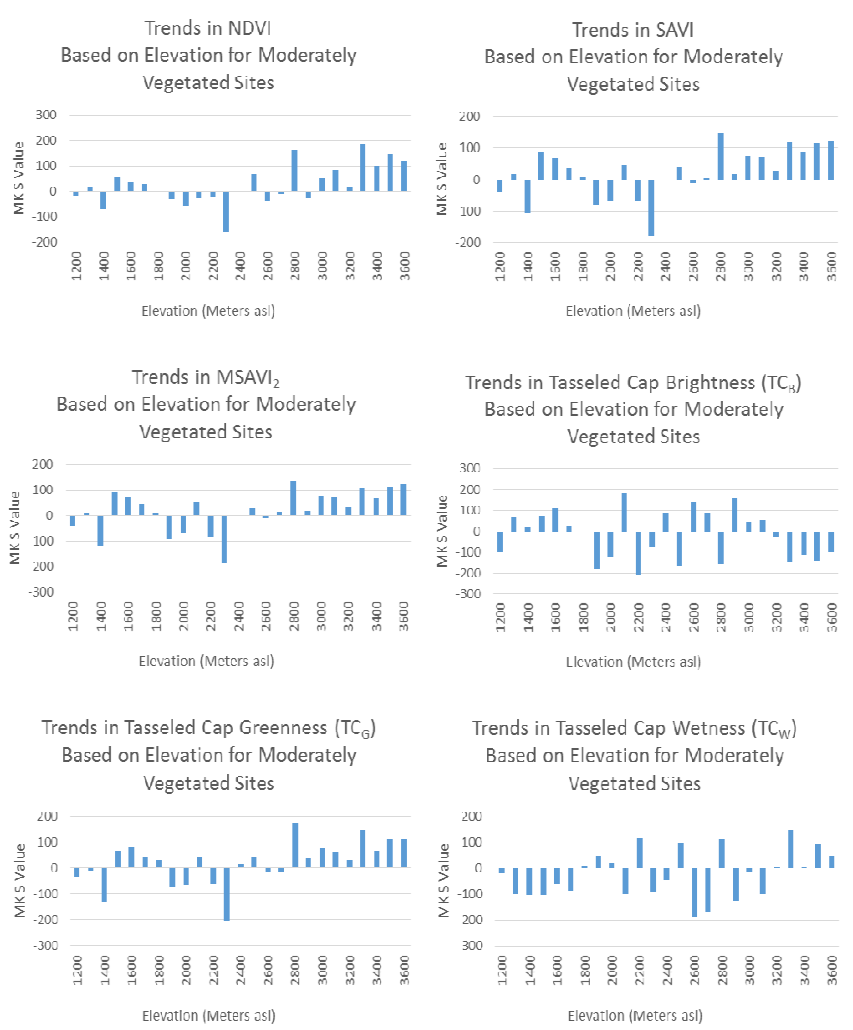

Figure 7. Trends in vegetation indices for moderately vegetated sites. 

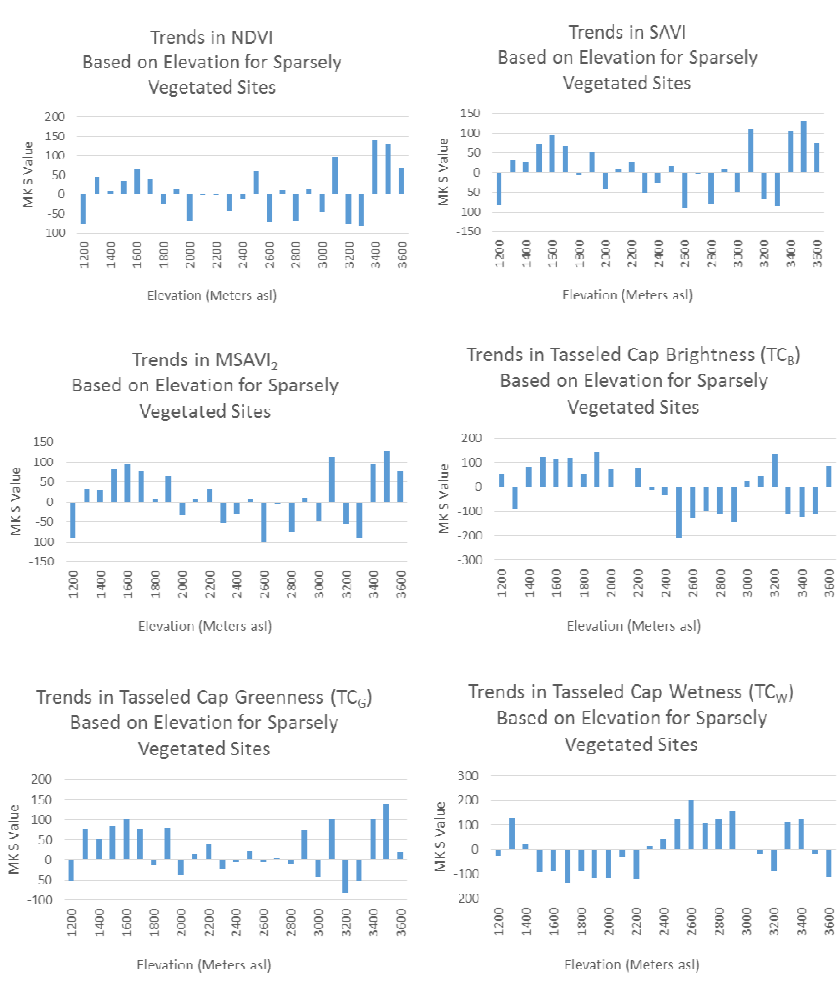

Figure 8. Trends in vegetation indices for sparsely vegetated sites.

Figure 8 shows that in the sparsely vegetated sites, the trends in vegetation indices and tasseled cap transformations are not as distinct as the spectral response. While the brightness and wetness transform trends are in good agreement, the vegetative indices show a more varied response. For example, the spectral responses in the visible bands suggest a decline in vegetation in the lower reaches of the watershed while the vegetation indices suggest an increase.

Since the near infrared response at the lower elevations is increasing, the structural complexity of the surface at these sites is increasing. These findings suggest that the compositions of the vegetation at the sites in the lower elevation are changing. The increase in $T C_{B}$ is consistent with a decline in overall surface cover in the lower elevations, while the decline in $T C_{B}$ is consistent with increased surface cover at the higher elevations. These data are consistent with the hypothesis of upslope migration suggested by the findings of the spectral response trend analysis for sparsely vegetated sites.

Looking at trends in surface reflectance and vegetation indices based solely on vegetative density, we see clear differences in the responses. As figure 9 demonstrates, densely vegetated sites show clear evidence of increases over the 30 year study period. Moderately and sparsely vegetated sites show no statistically significant change. This does not mean that change is not taking place at those sites, only that when averaged together, any changes are washed out. For example, with the sparsely vegetated sites, we observe declines in the lower half of the watershed and increases in the upper half. Therefore, when averaged across all sites, there appears to be no change. The primary finding from this comparison is that densely vegetated sites are seeing increased growth regardless of elevation.

The trends in surface reflectance and vegetative indices demonstrate significant changes are taking place across all regions of the watershed. Densely vegetated sites are seeing increases in growth at most elevation gradients with the exception of the 3000 meter to 3400 meter asl zone. Meanwhile, the least vegetated sites are seeing a distinct shift with increased vegetative cover in the upper half of the watershed and declines in the lower half of the watershed. Trends in the moderately vegetated sites do not show distinctive patterns based on elevation gradient.
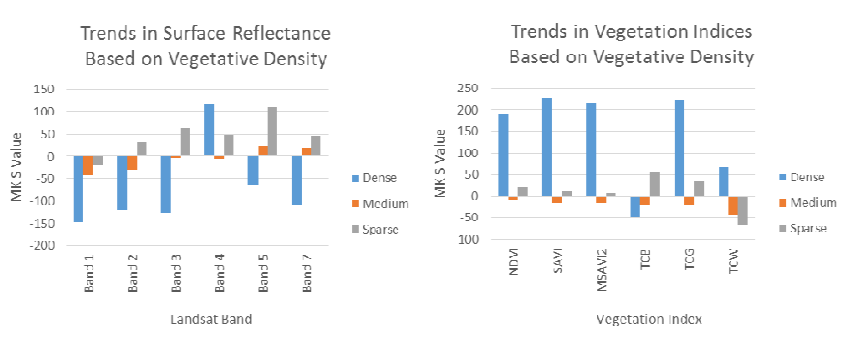

Figure 9. Trends in surface reflectance and vegetation indices based on vegetative density.

\subsection{Meteorological Data}

Ecological changes we have identified in the Big Pine Creek watershed are consistent with warming temperatures. In our previous paper, we identified statistically significant increases across the study area in both the maximum temperature $\left(\mathrm{T}_{\mathrm{MAX}}\right)$ and minimum temperature $\left(\mathrm{T}_{\mathrm{MIN}}\right)$. Looking at monthly trends, we found that for the maximum temperatures, the largest increases are taking place in the summer with smaller increases in the winter. Higher temperatures are an important factor in driving ecological changes since all biological processes are at their essence chemical reactions and increased temperatures will increase reaction rates. Increased biological activity can alter vegetative composition by changing the availability essential nutrients. Some nutrients will be more available through faster litter breakdown while some nutrients will be consumed at faster rates. This change in resource availability will drive changes in species composition to those species that are better suited to the new environmental conditions and resource make-up [29].

Precipitation and Big Pine Creek stream flow trends were also examined to determine if the moisture deficit conditions were impacting ecological responses over the study period. Here we found that although there was a slight decline in precipitation in the watershed, stream flow was slightly increasing which is consistent with warmer temperatures increasing the melt water contribution to the stream flow from the Palisade glacier [29]. In addition to driving biological activity, higher temperatures will also increase evapotranspiration. This will reduce moisture availability and stress vegetative species, especially those that are not drought tolerant. For the monthly minimum temperature trends, we see the largest increases are taking place in the summer and fall with smaller increases in the winter and spring. What 
these data demonstrate is that the summers are getting warmer and the winters are getting milder. This is an important finding since as discussed earlier, warmer summers will increase evapotranspiration during the dry season, increasing potential water stress in the vegetation. Milder winters will also result in reduced water storage capacity as less precipitation will fall as snow, which also results in reduced water supplies in the warmest time of the year [29].

The seasonal trends found in this analysis closely align with future climate regimes predicted by general circulation models showing milder wetter winters and hotter drier summers [30]. Lenihan et al. (2003) show that these future climate scenarios can produce shifts in the vegetative composition [30]. In particular, their biological distribution model simulations suggest a shift from shrubs to grasslands under these conditions [30]. The temperature trends demonstrate that the Big Pine Creek watershed is at heightened risk from climate change and highlight the need to develop strategies to adapt to the new climate paradigm.

\subsection{Confidence Levels}

Multitemporal satellite imagery is impacted by several factors including changes in sensor response, sensor stability, atmospheric effects, and illumination effects [31]. Geometric pixel registration errors are generally less than $1 / 2$ pixel [32]. Radiometric uncertainty for the TM data are approximately 5\% [33]. The USGS surface reflectance data set has been assessed against MODIS surface reflectance data and found to be highly correlated with discrepancies between 2.2 to 3.5 percent [34].

\section{Summary and Conclusions}

This study examined the changes in the ecosystem of the Big Pine Creek watershed as measured by trends in observed surface reflectance values along a 2500 meter elevation gradient at 75 sample sites over a 30 year time span from 1984 through 2013. Densely vegetated sites demonstrated significant increases in vegetative growth as evidenced by both declines in visible reflectance and increases in vegetative indices. Sparsely vegetated sites show a distinctive response pattern with vegetation increasing in the upper half of the watershed and declining in the lower half. Moderately vegetated sites show a mixed response with a few sites experiencing significant increases and a few showing significant declines. No elevation dependent pattern was evident for moderately vegetated sites.

Based on the findings of this study, we conclude that for densely vegetated sites, (those nearest permanent water sources), increased temperatures are driving increased vegetative growth with little evidence of compositional change. At sparsely vegetated sites, (those farthest from permanent sources of water), vegetation is moving upslope. At the upper reaches of the watershed, warmer temperatures are increasing the habitable zone for these sites while at the lower reaches, increased temperatures are driving an alteration of vegetative composition towards more drought tolerant species. The mixed responses seen at the moderately vegetated sites appear to be site specific with changes dictated by local conditions.

To determine what is driving the changes in vegetative surface cover, we look at trends in the environmental parameters of precipitation and temperature. Average monthly minimum and maximum temperatures show statistically significant upward trends [29]. Increased temperatures support increased photosynthetic activity as long as that process is not limited by other factors such as lack of water availability. In areas without water or other nutrient resource limitations, these conditions are conducive for increased vegetative surface cover resulting in stronger absorption in the visible region of the spectrum.

This study has clearly identified numerous changes taking place in the Big Pine Creek watershed over the last 30 years. Many of these changes are consistent with previous research related to climate change impacts on montane habitats. While this study has identified coarse trends in vegetative response, more detailed analysis of individual study sites is needed to both validate the findings from this study as well as to delineate the specific compositional changes that are occurring. Identifying how the individual components of each sample site have responded to altered environmental parameters will provide critical information on the ecological response to climate change in Alpine environments.

\section{References}

[1] M. Lindner, M.Maroschek, S.Netherer, A. Kremer, A.Barbati, J. Garcia-Gonzalo, R.Seidl, S.Delzon, P. Corona, M.Kolstrom, M.J.Lexer, and M. Marchetti, M., —Climate change impacts, adaptive capacity, and vulnerability of European forest ecosystems. Forest Ecology and Management, 259, pp. $698-709,2010$.

[2] P. Opdam, and D. Wascher, - Climate change meets habitat fragmentation: linking landscape and biogeographical scale levels in research and conservation. Biological Conservation, 117, pp. 285-297, 2004.

[3] M.R. Gasner, J.E. Jankowski, A.L.Ciecka, K.O. Kyle, K.O., and K.N. Rabenold, -Projecting the local impacts of climate change on a Central American montane avian community. Biological Conservation, 143, pp. 1250-1258, 2010 .

[4] R.J. Wilson, D. Gutierrez, J. Gutierrez, D. Martinez, R.Agudo, and V.J. Monserrat, - Changes to the elevational limits and extent of species ranges associated with climate change. Ecology Letters, 8, pp. 1138-1146, 2005.

[5] P. Vittoz, D.Cherix, Y. Gonseth, V.Lubini, R.Maggini, N. Zbinden, and S. Zumbach, -Climate change impacts on biodiversity in Switzerland: A review. Journal for Nature Conservation, 21, pp. 154-162, 2013.

[6] G.R. Walther, -Community and ecosystem responses to recent climate change, Philosophical Transactions of The Royal Society B, 365, pp. 2019-2024, 2010.

[7] J. Salick, F. Zhendong, and A. Byg, -Eastern Himalayan alpine plant ecology, Tibetan ethnobotony, and climate change. Global Environmental Change, 19, pp. 147-155, 2009. 
[8] A.E. Kelly, and M.L. Goulden, - Rapid shifts in plant distribution with recent climate change. Proceedings of the National Academy of Sciences (PNAS), 105(33), pp. 11823-11826, 2008.

[9] C.A. Wessman, -Imaging spectrometry for remote sensing of ecosystem processes. Advances in Space Research, 12 (7), pp. 361-368, 1992.

[10] R.D. Jackson, P.J. Pinter Jr., R.J.Reginato, and S.B. Idso, -Detection and evaluation of plant stresses for crop management decisions. IEEE Transactions on Geoscience and Remote Sensing, GE-24 (1), pp. 99-106, 1986.

[11] H.B. Musick, and R.E. Pelletier, -Response to soil moisture spectral indexes derived from bidirectional reflectance in thematic mapper wavebands. Remote Sensing of Environment, 25, pp. 167-184, 1988.

[12] H.D.Adams, M. Guardiola-Claramonte, G.A. BarronGafford, J.C. Villegas, D.D.Breshears, C.B. Zou, P.A. Troch, and T.E. Huxman, - Temperature sensitivity of drought-induced tree mortality portends increased regional die-off under global-change-type drought, PNAS, 106 (17), pp. $7063-7066,2009$.

[13] S.W. Todd, and R.M. Hoffer, -Responses of spectral indices to variations in vegetation cover and soil background. Photogrammetric Engineering \& Remote Sensing, 64 (9), pp. 915-921, 1998.

[14] J.E. Vogelmann, B.Tolk, and Z. Zhu, Z., -Monitoring forest changes in the southwestern United States using multitemporal Landsat data. Remote Sensing of Environment, 112, pp. 1739-1748, 2009.

[15] A.P. Williams, C.D. Allen, A.K.Macalady, D. Griffin, C.A Woodhouse, D.M.Meko, T.W.Swetnam, S.A. Rauscher, R.Seager, H.D.Grissino-Mayer, J.S. Dean, E.R. Cook, C.Gangodagamage, M.Cai, and N.G. McDowell, - Temperature as a potent driver of regional forest drought stress and tree mortality. Nature Climate Change, 3, pp. 292-297, 2013.

[16] O. Skre, and M. Naess, - $\mathrm{CO} 2$ and winter temperature effects on white birch. Chemosphere: Global Change Science, 1, pp. 469-483, 1999.

[17] D. J . Chmura, P.D. Anderson, G.T. Howe, C.A. Harrington, J.E.Halofsky, D.L. Peterson, D.C. Shaw, and B.J. St. Clair, -Forest responses to climate change in the northwestern United States: Ecophysiological foundations for adaptive management. Forest Ecology and Management, 261, pp. 1121-1142, 2011.

[18] A.J. Elmore, J.F. Mustard, and S.J. Manning, - Regional patterns of plant community response to changes in water: Owens Valley, California. Ecological Applications, 13 (2), pp. 443-460, 2003.

[19] N.D. Bowerman, and D.H. Clark, - Holocene glaciation of the central Sierra Nevada, California. Quaternary Science Reviews. 30, pp. 1067-1085, 2011.

[20] G.M. Kondolf, - Stream-groundwater interactions along streams of the Eastern Sierra Nevada California: Implications for assessing potential impacts of flow diversions. USDA Forest Service Gen. Tech. Rep. PSW110, pp. $352-359,1989$.
[21] V. Gond, D.G. De Pury, F.Veroustraete, and R. Cuelemans, - Seasonal variation in leaf area index, leaf chlorophyll and water content; scaling up to estimate fAPAR and carbon balance in a multilayer, multispecies temperate forest. Tree Physiology, 19, pp. 673-679, 1999.

[22] K.M. De Beurs, and G.M. Henebry, -A statistical framework for the analysis of long image time series. International Journal of Remote Sensing, 26 (8), pp. 1551$1573,2005$.

[23] J.G. Masek, E.F.Vermote, N.Saleous, R. Wolfe, F.G. Hall, F. Huemmrich, F. Gao, J.Kutler, and T.K.Lim, -A Landsat surface reflectance data set for North America, 1990-2000. IEEE Geoscience and Remote Sensing Letters, 3, pp. 68-72, 2006.

[24] Y.J. Kaufman, A.E. Wald, L.A. Remer, B.C.Gao, R.R. Li, and L. Flynn, -The MODIS $2.1 \mathrm{~m}$ channel Correlation with visible reflectance for use in remote sensing of aerosol. IEEE Transactions on Geoscience and Remote Sensing, 35 (5), pp. 1286-1298, 1997.

[25] J.W. Rouse, R.H. Haas, J.A. Schell and D.W. Deering, - Monitoring vegetation systems in the Great Plains with ERTS. Proc. Third ERTS-1 Symposium, NASA Goddard, NASA SP-351 pp. 309-317, 1974.

[26] A.R. Huete, - A soil-adjusted vegetation index. Remote Sensing of the Environment, 25, pp. 295-309, 1988.

[27] J. Qi, A.Chehbouni, A.R.Huete, Y.H. Kerr, and S. Sorooshian, S., -A modified soil-adjusted vegetation index. Remote Sensing of the Environment, 48, pp. 119126, 1994.

[28] E.P. Crist, - Short communication: A TM tasseled cap equivalent transformation for reflectance factor data. Remote Sensing of the Environment, 17, pp. 301-306, 1985.

[29] P.S. Sawyer, and H. Stephen, -The Big Pine Creek watershed and climate change: A trend analysis of Landsat surface reflectance and PRISM datasets over the last 3 decades. Advances in Space Research, 54, pp. 37-48, 2014.

[30] J.M. Lenihan, R.Drapek, D.Bachelet, and R.P. Nelson, -Climate change effects on vegetation distribution, carbon, and fire in California. Ecological Applications, 13 (6), pp. 1667 - 1681, 2003.

[31] S.M.Vicente-Serrano, F. Perez-Cabello, and T. Lasanta, -Assessment of radiometric correction techniques in analyzing vegetation variability and change using time series of Landsat imagery. Remote Sensing of Environment, 112, pp. 3916-3934, 2008.

[32] C.F. Schueler, and V.V. Salomonson, -Landsat Image Data Quality Studies. Advances in Space Research, 5 (5), pp. 1-11, 1985.

[33] G. Chander, B. Markham, and D.L. Helder, - Summary of current radiometric calibration coefficients for Landsat MSS, TM, ETM+, and EO-1 ALI sensors. Remote Sensing of Environment, 113, pp. 893-903, 2009.

[34] M. Feng, J.O. Sexton, C. Huang, J.G.Masek, E.F.Vermote, F. Gao, R.Narasimhan, S.Channan, R.E. Wolfe, and J.R. Townshend, -Global surface products from Landsat: Assessment using coincident MODIS observations, Remote Sensing of Environment, Vol. 134, pp. 276-293, 2013. 